\title{
Effet des ultrasons cavitants sur la coagulation du lait par les enzymes
}

\author{
par \\ C. RAHARINTSOA, M. L. GAULARD et C. ALAIS \\ Laboratoire de Biochimie Appliquée et Laboratoire d'Electronique \\ Université de Nancy I - 54037 Nancy
}

\section{INTRODUCTION}

Dans une précédente publication [9] nous avons exposé les résultats obtenus au cours d'une étude des effets de l'irradiation ultrasonore sur diverses enzymes coagulant le lait, d'origine animale ou fongique. La mesure de l'activité coagulante a montré des différences notables de sensibilité entre les enzymes ; l'eau oxygénée n'apparaît qu'en très faible quantité et ne paraît pas jouer de rôle dans l'action dénaturante.

Nous avons poursuivi cette étude en mesurant l'effet de l'irradiation sur l'activité protéolytique des enzymes précédentes ; puis l'effet de l'irradiation sur le lait lui-même et sur le mélange réactionnel lait + enzyme, en déterminant l'aptitude à la coagulation et les propriétés rhéologiques au caillé obtenu. Les résultats font l'objet de cette deuxième publication.

\section{MATERIEL ET METHODES}

\subsection{Irradiation}

Nous avons conservé le même dispositif [9] ; cuve thermostatée de $7 \times 4 \mathrm{~cm}$, avec triplet de Langevin, fréquence de résonnance de $27 \mathrm{KHz}$, tension appliquée pouvant aller jusqu'à 400 volts.

\subsection{Enzymes}

Nous avons utilisé les mêmes enzymes que celles décrites précédemment [9] après une purification sommaire par longue dialyse 
contre l'eau : chymosine et pepsine bovines de Chr. Hansen ; pepsine porcine de Sigma; enzymes de Mucor miehei, Mm (Fro) de Rapidase et $\mathrm{Mm}$ (Ren) de Novo ; enzyme d'Endothia parasitica, Ep, de Chas Pfizer, enzyme de Mucor pusillus, Mp de Meito-Sangyo.

\subsection{Activité protéolytique}

On mesure l'accroissement de l'azote non protéique, soluble dans l'acide trichloracétique (TCA) après action des enzymes sur la caséine entière de vache en solution à $2 \mathrm{p} .100$, à $\mathrm{pH} 6,7$ et à $30^{\circ} \mathrm{C}$.

Les produits de la réaction primaire sont solubles dans le TCA 12 p. 100 de concentration finale, et ceux de la protéolyse générale dans du TCA à 2 p. 100. L'azote est dosé par la méthode micro-Kjeldahl. Chaque enzyme est utilisée à raison de $0,05 \mathrm{uP} / \mathrm{ml}$ de substrat $(3,4)$.

\subsection{Mesure de la viscosité}

Nous avons utilisé un viscosimètre rotatif à cylindres coaxiaux qui sert à la détermination de la viscosité dynamique de substances fluides (type RN de VEB-Feinmess). Le principe de mesure est basé sur le courant Searle-Couette. L'échantillon de lait $(13,5 \mathrm{ml})$ est introduit dans l'interstice circulaire entre un cylindre intérieur rotatif $(160 \mathrm{t} / \mathrm{mn})$ et un cylindre extérieur fixe. L'appareil est muni d'un bain thermostaté. Il est étalonné avec de l'eau distillée entre chaque mesure, à la température de $20^{\circ} \mathrm{C}$.

\subsection{Mesure des paramètres rhéologiques du caillé}

Elle a été faite au moyen du Thrombocord (LARA) dont le principe est le même que celui du Thrombélastographe. Il se compose d'une cuve cylindrique de $8 \mathrm{~mm}$ de diamètre intérieur et de $12 \mathrm{~mm}$ de profondeur dans laquelle est mis le mélange à coaguler. Cette cuve est soumise à un mouvement d'oscillation périodique autour de son axe vertical. Un piston de mesure est abaissé dans le liquide. Au moment où celui-ci coagule, la cuve et le piston deviennent solidaires et les mouvements de la cuve sont transmis au piston qui est alors entraîné. Le spot lumineux réfléchi sur le miroir lié au portepiston se déplace suivant les mêmes mouvements d'oscillation qui seront transcrits sur un papier baryté. Le thrombélastogramme obtenu, en forme de diapason, permet de déterminer trois paramètres :

— $\mathrm{r} »$ : correspond à la partie longitudinale du tracé ; il mesure le temps écoulé depuis l'emprésurage jusqu'au moment où la largeur du tracé atteint $1 \mathrm{~mm}$ (c'est un temps de coagulation) ;

- « K »: représente le temps mis par le caillé pour acquérir certaines propriétés mécaniques telles que les deux branches du tracé s'écartent d'une distance fixée. Ce paramètre mesure une vitesse de raffermissement : si le coagulum évolue rapidement, $\mathrm{K}$ sera faible et 
inversement. Pour éliminer l'effet des variations du temps de coagulation, on a exprimé $\mathrm{K} / \mathrm{r}$. Habituellement, on mesure le $\mathrm{K}_{20}$ (écartement de $20 \mathrm{~mm}$ ) ; mais dans les expériences où l'amplitude est faible, on a mesuré le $\mathrm{K}_{15}$;

- «Am » : correspond à la mesure en mm de l'écartement maximum des deux branches; il représente la fermeté du caillé avant l'exudation du sérum.

\subsection{Dosage du calcium}

Il a été fait par spectrophotométrie d'absorption atomique (appareil A.A.S. Varian-Techtron). Le dosage, utilisant le chlorure de Lanthane à 5 p. 100 comme tampon spectral, est effectué sur une dilution de l'échantillon au 1/200. Cette solution est pulvérisée dans la flamme air-acétylène de l'appareil. Chaque valeur est rapportée à une gamme étalon de 2 à $20 \mathrm{mg} / \mathrm{l}$ de chlorure de calcium.

Pour l'ultrafiltration du lait, nous avons utilisé la cellule Amicon et des membranes Diaflo type UM 2 (masse moléculaire d'exclusion inférieure à 1000). Elle se fait sous pression d'azote de 3 bars. On récupère un volume de filtrat égal à la moitié du volume du lait originel. Le surnageant est obtenu en ultracentrifugeant le lait à $300000 \mathrm{~g}$ pendant $30 \mathrm{mn}$.

\section{RESULTATS}

\subsection{Effet des ultrasons sur l'activité protéolytique des enzymes}

Le tableau 1 montre que l'activité protéolytique mesurée par la libération d'azote non protéique (NPN) dans une solution de caséine de vache, est diversement affectée par l'irradiation selon l'enzyme étudiée, irradiation effectuée à $16^{\circ} \mathrm{C}$.

La chymosine perd rapidement et progressivement son activité ; après seulement $20 \mathrm{mn}$ d'irradiation, la libération de NPN est réduite de près de la moitié ; elle devient nulle après $120 \mathrm{mn}$, qu'il s'agisse du NPN soluble dans 12 p. 100 d'acide trichloracétique ou du NPN soluble dans 2 p. 100.

La pepsine bovine est également sensible à l'irradiation, mais la chute est moins rapide qu'avec la chymosine ; cependant, après $90 \mathrm{mn}$, l'activité devient nulle. On observe une nette différence de comportement de la pepsine porcine qui est plus résistante que la précédente ; après $120 \mathrm{mn}$ on retrouve encore 50 p. 100 de l'activité.

Les protéases fongiques sont peu ou pas sensibles à l'irradiation. Les deux enzymes de Mucor miehei se comportent de la même manière, leur activité reste inchangée. L'enzyme Ep est faiblement inactivée ; l'enzyme Mp l'est un peu plus fortement. 
TABLEAU 1. - Effet de l'irradiation ultrasonore sur l'activité protéolytique*

\begin{tabular}{|c|c|c|c|c|c|c|c|c|c|c|}
\hline \multirow{2}{*}{ Enzyme ${ }^{* *}$} & \multirow{2}{*}{$\begin{array}{l}\text { TCA } \\
\text { p. } 100\end{array}$} & \multicolumn{2}{|c|}{ NPN p. $100 \mathrm{NT}$} & \multicolumn{7}{|c|}{$\begin{array}{l}\text { Libération de NPN }(a=100) \text { dans la caséine } \\
\text { après irradiation des enzymes }(\mathrm{mn})\end{array}$} \\
\hline & & temps 0 & $\begin{array}{l}\text { augmentation } \\
\text { après } 20 \mathrm{mn} \\
\text { (a) }\end{array}$ & 20 & 30 & 60 & 90 & 120 & 180 & 240 \\
\hline \multirow{2}{*}{ Chymosine } & 2 & 0,56 & 1,82 & 61 & 44,5 & 19,2 & 5,0 & 2,7 & 0 & 0 \\
\hline & 12 & 0,53 & 0,79 & 52 & 29 & 6,8 & 8,9 & 2,5 & 0 & 0 \\
\hline Pepsine porcine & 12 & 0,47 & 0,22 & 100 & 64 & 64 & 59 & 50 & & \\
\hline Pepsine bovine & 12 & 0,47 & 0,22 & 91 & 63 & 41 & 14 & 0 & & \\
\hline Enzyme Mm (Fro) & 12 & 0,47 & 0,52 & 100 & 100 & 100 & 100 & 100 & & \\
\hline Enzyme Mm (Ren) & 12 & 0,47 & 0,52 & 100 & 100 & 100 & 100 & 100 & & \\
\hline Enzyme Ep & 12 & 0,50 & 0,46 & 100 & 91 & 89 & 89 & 89 & & \\
\hline Enzyme Mp & 12 & 0,51 & 0,38 & 100 & 100 & 94 & 89 & 79 & & \\
\hline
\end{tabular}

* Substrat : caséine entière de vache 2 p. $100 ; \mathrm{pH} 6,5 ; 30^{\circ} \mathrm{C}$.

** Les doses utilisées correspondent à $0,05 \mathrm{UP} / \mathrm{ml}$ dans tous les cas (voir texte). 
Il y a un parallélisme entre ces résultats et ceux publiés précédemment [9] relatifs à l'activité coagulante, ce qui est normal si l'on considère que la coagulation est la conséquence de la réaction protéolytique primaire, comme cela a été montré par Alais et al. [1]. Cependant, dans le cas de la pepsine bovine, l'activité protéolytique semble disparaître après $120 \mathrm{mn}$ d'irradiation alors qu'on observe encore une activité coagulante (réduite 2,7 fois) ; il est possible qu'une faible activité protéolytique, non mesurable sous forme de NPN, persiste.

\subsection{Conséquences de l'irradiation du lait sur l'aptitude à la coagulation}

L'irradiation du lait écrémé reconstitué, pendant $30 \mathrm{mn}$, modifie un peu son goût ; mais après $60 \mathrm{mn}$ de traitement un goût de brûlé ou de cuit apparaît assez fort. Une altération comparable du goût du lait écrémé soumis à la lumière solaire a été attribuée soit à une modification de certains acides aminés, notamment la méthionine transformée en méthional, soit à l'activation des groupes sulfhydryles et à la formation de sulfures, aux dépens de la cystéine [11].

L'irradiation du lait cru entier provoque également l'apparition d'un goût anormal mais plus rapidement et plus fortement ; il s'agit probablement d'une association du goùt de cuit ou de brûlé et de la saveur oxydée, résultant de l'oxydation des acides gras polyinsaturés.

Le lait reconstitué est un peu moins facilement coagulable par la chymosine et par les enzymes de Mucor miehei (Fro, Ren) après irradiation. Les résultats, pour une durée de $60 \mathrm{mn}$, se trouvent dans le tableau 2. L'allongement du temps de coagulation est plus grand pour les faibles concentrations en enzyme. Les valeurs sont un peu moins élevées pour la chymosine que pour les enzymes $\mathrm{Mm}$. On sait que ces derniers sont plus sensibles que la chymosine à la concentration en calcium ionisé. Il se pourrait que l'irradiation, comme les traitements thermiques, déplace l'équilibre entre les formes solubles et insolubles de Ca.

Des essais de coagulation avec sept dilutions différentes ont donné, avant comme après irradiation, des droites lorsque l'on porte en abscisse l'inverse de la concentration et en ordonnée le temps, c'est-à-dire que la règle de Storch et Segelke est observée.

Dans le cas du lait cru, les résultats sont différents. Avec la chymo sine agissant sur le lait irradié durant 30 ou $60 \mathrm{mn}$, on n'observe pas d'écart notable dans le temps de coagulation. Quatre essais ont été réalisés avec différentes dilutions de l'enzyme donnant des temps de coagulation allant de 5 à $30 \mathrm{mn}$. Les courbes sont des droites à peu près parallèles et proches les unes des autres. Dans un cas elles sont confondues ; dans l'autre le lait irradié coagule un peu plus lentement que l'autre ; dans les deux autres cas c'est le contraire. 


\section{TABLEAU 2}

Coagulabilité du lait reconstitué après une irradiation de $60 \mathrm{mn}$

\begin{tabular}{l|c|c|c}
\hline \multirow{2}{*}{ Enzyme } & $\begin{array}{c}\text { Concentration } \\
\text { p. } 100 \mathrm{ml}\end{array}$ & $\begin{array}{c}\text { Temps de } \\
\text { coagulation à 32 } \\
\text { avant traitement } \\
(\mathrm{mn})\end{array}$ & $\begin{array}{c}\text { Allongement } \\
\text { du temps } \\
\text { de coagulation } \\
\text { après traitement* }\end{array}$ \\
\cline { 2 - 3 } Chymosine & 0,02 & & 107 \\
Enzyme Mm (Fro) & 0,004 & 3,7 & 113 \\
Enzyme Mm (Ren) & 0,003 & 3,8 & 110 \\
& 0,0006 & 14,9 & 125 \\
& 0,008 & 3,3 & 110 \\
& 0,0016 & 13,9 & 129 \\
& & & \\
\hline
\end{tabular}

* Temps de coagulation avant traitement : 100 .

Avec les deux enzymes de Mucor miehei, dans le lait non irradié on observe une cassure de la courbe pour une dilution de l'enzyme donnant un temps de coagulation de 15 à $20 \mathrm{mn}$. On retrouve l'inhibition démontrée par Alais et al [2]. L'irradiation réduit nettement cette inhibition ; on peut même obtenir une droite, comme dans un lait chauffé à $70^{\circ} \mathrm{C}$ et plus, si la durée d'irradiation est suffisante ; avec un lait (fig. 1), cela s'est produit pour une durée de $30 \mathrm{mn}$, mais avec un autre lait, la courbe n'est redevenue droite qu'après $120 \mathrm{mn}$ d'irradiation. On a remarqué au cours de quatre expériences, avec une dose d'enzyme donnant avant dilution un temps de coagulation de $5 \mathrm{mn}$, que l'inhibition de l'enzyme Mm (Fro) est un peu plus forte que celle de Mm (Ren).

On sait [2] que l'inhibiteur des protéases coagulantes des Mucor se trouve dans la fraction des protéines solubles du lait et probablement parmi les immunoglobulines et qu'elle est détruite par un chauffage modéré du lait $\left(70^{\circ} \mathrm{C}, 20 \mathrm{~s}\right)$. Il est donc vraisemblable que les ultrasons possèdent une action dénaturante du même type. Des effets comparables ont été observés dans le sérum sanguin humain : Verain et al. [13] ont montré une diminution progressive de l'activité complémentaire du sérum et une dénaturation des constituants globuliniques par suite du traitement par les ultrasons. 


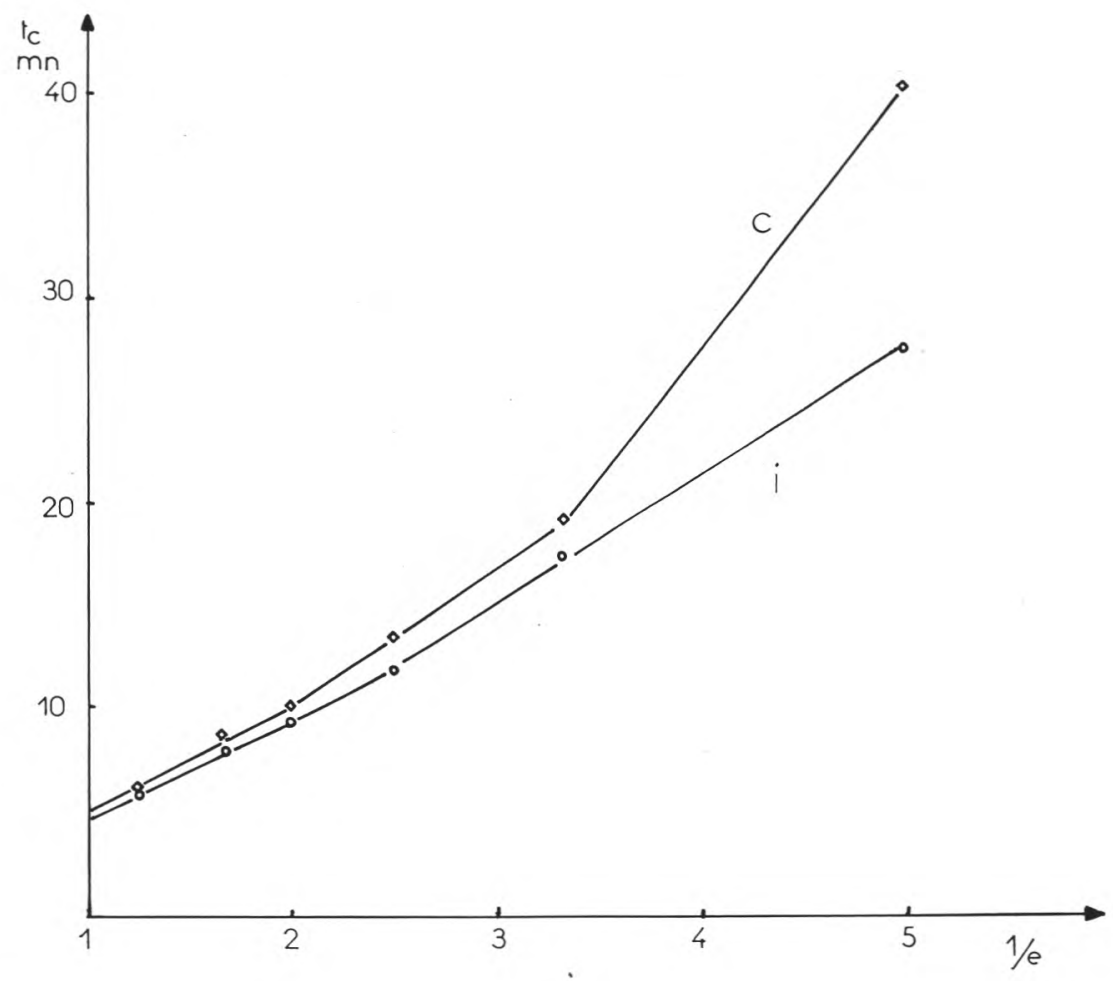

fig. 1

Temps de coagulation (tc) du lait cru (c) et du lait cru irradié $30 \mathrm{mn}$ (i), en fonction de la dilution de l'enzyme (1/e) de Mucor miehei (Ren).

\subsection{Effets de l'irradiation sur la viscosité du lait}

L'irradiation a été effectuée à $18^{\circ} \mathrm{C}$ et la mesure de la viscosité à $20^{\circ} \mathrm{C}$. Les résultats sont résumés dans le tableau 3. Il se produit une légère baisse ; elle est la plus forte dans le lait cru entier ; le lait cru écrémé a une plus faible viscosité et l'irradiation ne la diminue que faiblement. L'effet des ultrasons concerne donc aussi bien la phase lipidique globulaire que les protéines, mais il faut souligner le fait que cet effet est contraire à celui de l'homogénéisation des globules gras du lait sous pression qui, elle, accroît la viscosité. Beck et Rouyer [5] avaient déjà constaté une faible chute de viscosité dans le lait reconstitué irradié. 
TABLEAU 3

Variation de la viscosité dans le lait irradié*

\begin{tabular}{|c|c|c|c|}
\hline \multirow{3}{*}{$\begin{array}{c}\text { Durée } \\
\text { d'irradiation }\end{array}$} & \multicolumn{3}{|c|}{ Lait } \\
\hline & \multirow{2}{*}{ reconstitué } & \multicolumn{2}{|c|}{ cru } \\
\hline & & entier & écrémé \\
\hline 0 & 2,08 & 2,24 & 1,92 \\
\hline 10 & 1,98 & 2,08 & 1,87 \\
\hline 20 & 1,87 & 1,85 & 1,82 \\
\hline 30 & 1,87 & 1,77 & 1,76 \\
\hline 60 & 1,83 & 1,77 & 1,76 \\
\hline (chute 0-60) & $(0,25)$ & $(0,47)$ & $(0,16)$ \\
\hline
\end{tabular}

* En $\mathrm{cp}$, à $20^{\circ} \mathrm{C}$, eau $=1,04$.

\subsection{Action des ultrasons sur le mélange réactionnel lait-enzyme}

La difficulté majeure de ce genre d'étude est le maintien de la température à une valeur donnée, car la variation ultrasonore provoque dans le milieu où elle prend naissance, une brusque élévation de température ; or on connaît la grande influence qu'a ce paramètre sur le temps de coagulation. De ce fait, des essais d'irradiation du mélange lait + enzyme à la température ambiante ou à la température habituelle de coagulation, $32^{\circ} \mathrm{C}$, n'ont pas donné de résultats reproductibles.

Des essais d'irradiation de longue durée, de 20 à $60 \mathrm{mn}$, ont été réalisés à $13,5^{\circ} \mathrm{C}$; ensuite l'épreuve de coagulation est faite à $32^{\circ} \mathrm{C}$. Le témoin est placé dans les mêmes conditions de température.

Dans le cas de la chymosine, le tableau 4 montre que l'irradiation du mélange ne change pratiquement pas le temps de coagulation du lait reconstitué ou du lait cru. Il y a donc un grand effet protecteur de l'enzyme par le lait ; car une irradiation de même durée dans l'eau 
TABLEAU 4. - Irradiation du mélange lait + chymosine

\begin{tabular}{|c|c|c|c|}
\hline \multirow{2}{*}{ Chymosine p. $100 \mathrm{ml}$} & \multirow{2}{*}{$\begin{array}{l}\text { Durée d'irradiation } \\
\text { à } 13,5^{\circ} \mathrm{C}(\mathrm{mn})\end{array}$} & \multicolumn{2}{|c|}{$\begin{array}{l}\text { Allongement du temps de coagulation } \\
\qquad a \mathrm{à} 32^{\circ} \mathrm{C}^{*}\end{array}$} \\
\hline & & lait reconstitué & lait cru \\
\hline $\begin{array}{c}0,02 \\
" \\
"\end{array}$ & $\begin{array}{l}20 \\
30 \\
60\end{array}$ & $\begin{array}{l}101 \\
101 \\
101\end{array}$ & $\begin{array}{c}99 \\
100,5 \\
99\end{array}$ \\
\hline $\begin{array}{c}0,008 \\
" \\
"\end{array}$ & $\begin{array}{l}20 \\
30 \\
60\end{array}$ & $\begin{array}{l}101 \\
101 \\
101\end{array}$ & $\begin{array}{c}99 \\
100 \\
99,5\end{array}$ \\
\hline $\begin{array}{l}0,004 \\
" \\
"\end{array}$ & $\begin{array}{l}20 \\
30 \\
60\end{array}$ & $\begin{array}{l}100,5 \\
100,5 \\
105\end{array}$ & $\begin{array}{l}100 \\
99 \\
97,7\end{array}$ \\
\hline
\end{tabular}

* Temps de coagulation du témoin : 100.

TABLEAU 5. - Irradiation du mélange lait + enzyme $\mathrm{Mm}$

\begin{tabular}{|c|c|c|c|c|}
\hline \multicolumn{2}{|c|}{ Enzyme Mm p. $100 \mathrm{ml}^{*}$} & \multirow{2}{*}{$\begin{array}{c}\text { Durée } \\
\text { d'irradiation } \\
\text { à } 13,5^{\circ} \mathrm{C}(\mathrm{mn})\end{array}$} & \multicolumn{2}{|c|}{$\begin{array}{l}\text { Evolution du temps de } \\
\text { coagulation à } 32^{\circ} \mathrm{C} \\
\text { dans le lait } \mathrm{cru}^{* * *}\end{array}$} \\
\hline Fro & Ren & & Fro & Ren \\
\hline $\begin{array}{c}0,003 \\
\text { \# }\end{array}$ & $\begin{array}{c}0,008 \\
»\end{array}$ & $\begin{array}{l}30 \\
60\end{array}$ & $\begin{array}{l}101 \\
100\end{array}$ & $\begin{array}{l}101 \\
101\end{array}$ \\
\hline $\begin{array}{c}0,0009 \\
\text { » }\end{array}$ & $\begin{array}{c}0,0024 \\
»\end{array}$ & $\begin{array}{l}30 \\
60\end{array}$ & $\begin{array}{l}95,6 \\
93,4\end{array}$ & $\begin{array}{c}100,5 \\
98\end{array}$ \\
\hline $\begin{array}{c}0,0006 \\
\text { » }\end{array}$ & $\begin{array}{c}0,0016 \\
》\end{array}$ & $\begin{array}{l}30 \\
60\end{array}$ & $\begin{array}{l}91 \\
74,5\end{array}$ & $\begin{array}{l}88,3 \\
85,6\end{array}$ \\
\hline
\end{tabular}

* Sur une même ligne, les concentrations utilisées donnent approximativement le même temps de coagulation du lait témoin.

** Temps de coagulation du témoin non irradié : 100 . 
provoque une perte notable d'activité (pour la plus faible concentration, après $60 \mathrm{mn}$, il n'y a presque plus d'activité coagulante).

Dans le cas des enzymes Mm ajoutées au lait cru, le tableau 5 montre que le temps de coagulation dans le lait cru se raccourcit sensiblement après irradiation pour les plus faibles concentrations. L'action des ultrasons sur le lait est donc prépondérante, puisqu'elle lève l'inhibition de ces enzymes comme nous l'avons vu plus haut.

\subsection{Modification des paramètres rhéologiques de la coagulation du lait traité par les ultrasons. Proportion du calcium soluble}

Le lait cru a été irradié durant 30 et $60 \mathrm{mn}$ à la température de $16^{\circ} \mathrm{C}$, juste avant l'addition de l'enzyme coagulante. Les tableaux 6 et 7 présentent l'ensemble des résultats correspondant aux deux catégories ; dans les cas où l'amplitude maximale était inférieure à 20 on a calculé $K_{15} / r$, et non pas $K_{20} / r$. L'irradiation d'une durée de $30 \mathrm{mn}$ donne presque toujours une valeur comprise entre celle du lait non traité et celle du lait irradié durant $60 \mathrm{mn}$. C'est cette dernière valeur qui a servi à calculer les variations des paramètres résumées dans le tableau 8.

L'irradiation ne modifie pas sensiblement le temps de coagulation thrombélastographique par la chymosine et la pepsine bovine. Dans tous les autres cas on observe une accélération de la coagulation, surtout dans le cas de la pepsine porcine où le lait irradié $60 \mathrm{mn}$ coagule approximativement trois fois plus vite que le lait cru. Avec cette enzyme, très sensible au pH dans cette zone, l'expérience a été refaite à un $\mathrm{pH}$ plus bas ; mais à $\mathrm{pH}$ 6,50 les résultats sont proches de ceux obtenus à $\mathrm{pH}$ 6,75. Le raccourcissement du temps de coagulation est compréhensible pour les enzymes de Mucor qui trouvent dans le lait cru un inhibiteur sensible aux ultrasons comme au chauffage [2] ; par contre, il est difficile à expliquer dans le cas de la pepsine porcine et de l'enzyme Ep, pour lesquels on n'a pas démontré d'inhibition dans le lait cru.

Un effet général remarquable de l'irradiation, observé dans tous les cas, est d'accélérer le raffermissement du caillé (abaissement de $\mathrm{K}_{20} / \mathrm{r}$ ) et d'augmenter la fermeté finale (augmentation de Am). On l'observe même pour la chymosine, avec une valeur de Am presque doublée. Le plus fort accroissement de fermeté s'observe avec la pepsine porcine. La figure 2 met bien en évidence les modifications de la coagulation par une même dose d'enzyme, du fait de l'irradiation.

L'abaissement du pH après l'irradiation est trop faible pour expliquer des variations notables des paramètres, même dans le cas où la coagulation est obtenue par la pepsine porcine, car avec un écart de 0,02 on a à peu près le même effet qu'avec un écart de 0,04 .

Nous avons cherché à savoir si un changement dans l'équilibre entre les formes solubles et insolubles du calcium pouvait être mis en cause. 
TABLEAU 6. - Coagulation du lait irradié par les enzymes animales

\begin{tabular}{|c|c|c|c|c|c|}
\hline \multirow{2}{*}{ Enzyme } & \multirow{2}{*}{$\begin{array}{l}\text { Concentration } \\
\mathrm{g} / 100 \mathrm{ml}\end{array}$} & \multirow{2}{*}{ Détermination } & \multicolumn{3}{|c|}{ Lait } \\
\hline & & & non traité & irradié $30 \mathrm{mn}$ & irradié $60 \mathrm{mn}$ \\
\hline Chymosine & 0,002 & $\begin{array}{c}\mathrm{pH} \\
\mathrm{r} \\
\mathrm{K}_{20} / \mathrm{r} \\
\mathrm{Am}\end{array}$ & $\begin{array}{c}6,64 \\
7,3 \\
3,45 \\
20,0\end{array}$ & $\begin{array}{c}6,61 \\
7,3 \\
3,56 \\
24,0\end{array}$ & $\begin{array}{c}6,60 \\
7,3 \\
2,46 \\
36,0\end{array}$ \\
\hline Pepsine bovine & 0,01 & $\begin{array}{c}\mathrm{pH} \\
\mathrm{r} \\
\mathrm{K}_{20} / \mathrm{r} \\
\mathrm{Am}\end{array}$ & $\begin{array}{l}6,68 \\
5,8 \\
3,1 \\
23,5\end{array}$ & $\begin{array}{c}6,66 \\
5,8 \\
2,02 \\
33,0\end{array}$ & $\begin{array}{c}6,64 \\
6,0 \\
0,75 \\
45,5\end{array}$ \\
\hline Pepsine porcine I & 0,002 & $\begin{array}{c}\mathrm{pH} \\
\mathrm{r} \\
\mathrm{K}_{20} / \mathrm{r} \\
\mathrm{Am}\end{array}$ & $\begin{array}{c}6,75 \\
9,0 \\
16, \overline{5}\end{array}$ & $\begin{array}{c}6,72 \\
3,05 \\
1,15 \\
57,5\end{array}$ & $\begin{array}{c}6,71 \\
2,5 \\
0,73 \\
68,0\end{array}$ \\
\hline Pepsine porcine II & 0,001 & $\begin{array}{c}\mathrm{pH} \\
\mathrm{r} \\
\mathrm{K}_{15} / \mathrm{r} \\
\mathrm{Am}\end{array}$ & $\begin{array}{c}6,4 \\
6,0 \\
2,75 \\
17,0\end{array}$ & $\begin{array}{l}- \\
\overline{-}\end{array}$ & $\begin{array}{c}6,38 \\
2,6 \\
0,96 \\
55\end{array}$ \\
\hline
\end{tabular}


TABLEAU 7. - Coagulation du lait irradié par les enzymes fongiques

\begin{tabular}{|c|c|c|c|c|c|}
\hline \multirow{2}{*}{ Enzyme } & \multirow{2}{*}{$\begin{array}{l}\text { Concentration } \\
\mathrm{g} / 100 \mathrm{ml}\end{array}$} & \multirow{2}{*}{ Détermination } & \multicolumn{3}{|c|}{ Lait } \\
\hline & & & non traité & irradié $30 \mathrm{mn}$ & irradié $60 \mathrm{mn}$ \\
\hline Mm (Fro) I & 0,003 & $\begin{array}{c}\mathrm{pH} \\
\mathrm{r} \\
\mathrm{K}_{20} / \mathrm{r} \\
\mathrm{Am}\end{array}$ & $\begin{array}{c}6,74 \\
7,8 \\
1,7 \\
25,0\end{array}$ & $\begin{array}{c}6,70 \\
6,55 \\
1,9 \\
30,5\end{array}$ & $\begin{array}{c}6,69 \\
4,55 \\
0,93 \\
49,0\end{array}$ \\
\hline Mm (Fro) II & 0,003 & $\begin{array}{c}\mathrm{pH} \\
\mathrm{r} \\
\mathrm{K}_{15} / \mathrm{r} \\
\mathrm{Am}\end{array}$ & $\begin{array}{c}6,5 \\
6,0 \\
1,54 \\
19,0\end{array}$ & $\begin{array}{l}\overline{-} \\
\overline{-}\end{array}$ & $\begin{array}{c}6,46 \\
4,0 \\
0,69 \\
49,0\end{array}$ \\
\hline Mm (Ren) I & 0,008 & $\begin{array}{c}\mathrm{pH} \\
\mathrm{r} \\
\mathrm{K}_{20} / \mathrm{r} \\
\mathrm{Am}\end{array}$ & $\begin{array}{r}6,7 \\
7,0 \\
\overline{21,0}\end{array}$ & $\begin{array}{l}6,68 \\
4,55 \\
1,0 \\
51,5\end{array}$ & $\begin{array}{c}6,66 \\
3,8 \\
0,92 \\
53,0\end{array}$ \\
\hline Mm (Ren) II & 0,008 & $\begin{array}{c}\mathrm{pH} \\
\mathrm{r} \\
\mathrm{K}_{15} / \mathrm{r} \\
\mathrm{Am}\end{array}$ & $\begin{array}{c}6,50 \\
6,25 \\
1,96 \\
16,0\end{array}$ & $\begin{array}{l}- \\
\overline{-}\end{array}$ & $\begin{array}{c}6,46 \\
3,5 \\
0,78 \\
56\end{array}$ \\
\hline Ep & 0,002 & $\begin{array}{c}\mathrm{pH} \\
\mathrm{r} \\
\mathrm{K}_{20} / \mathrm{r} \\
\mathrm{Am}\end{array}$ & $\begin{array}{c}6,65 \\
4,3 \\
4,5 \\
20,0\end{array}$ & $\begin{array}{l}6,63 \\
3,3 \\
1,1 \\
50\end{array}$ & $\begin{array}{c}6,61 \\
2,8 \\
0,71 \\
56,5\end{array}$ \\
\hline $\mathrm{Mp}$ & 0,002 & $\begin{array}{c}\mathrm{pH} \\
\mathrm{r} \\
\mathrm{K}_{20} / \mathrm{r} \\
\mathrm{Am}\end{array}$ & $\begin{array}{c}6,75 \\
9,8 \\
4,2 \\
20,0\end{array}$ & $\begin{array}{c}6,73 \\
6,05 \\
1,3 \\
45,5\end{array}$ & $\begin{array}{c}6,70 \\
4,8 \\
1,05 \\
59,5\end{array}$ \\
\hline
\end{tabular}



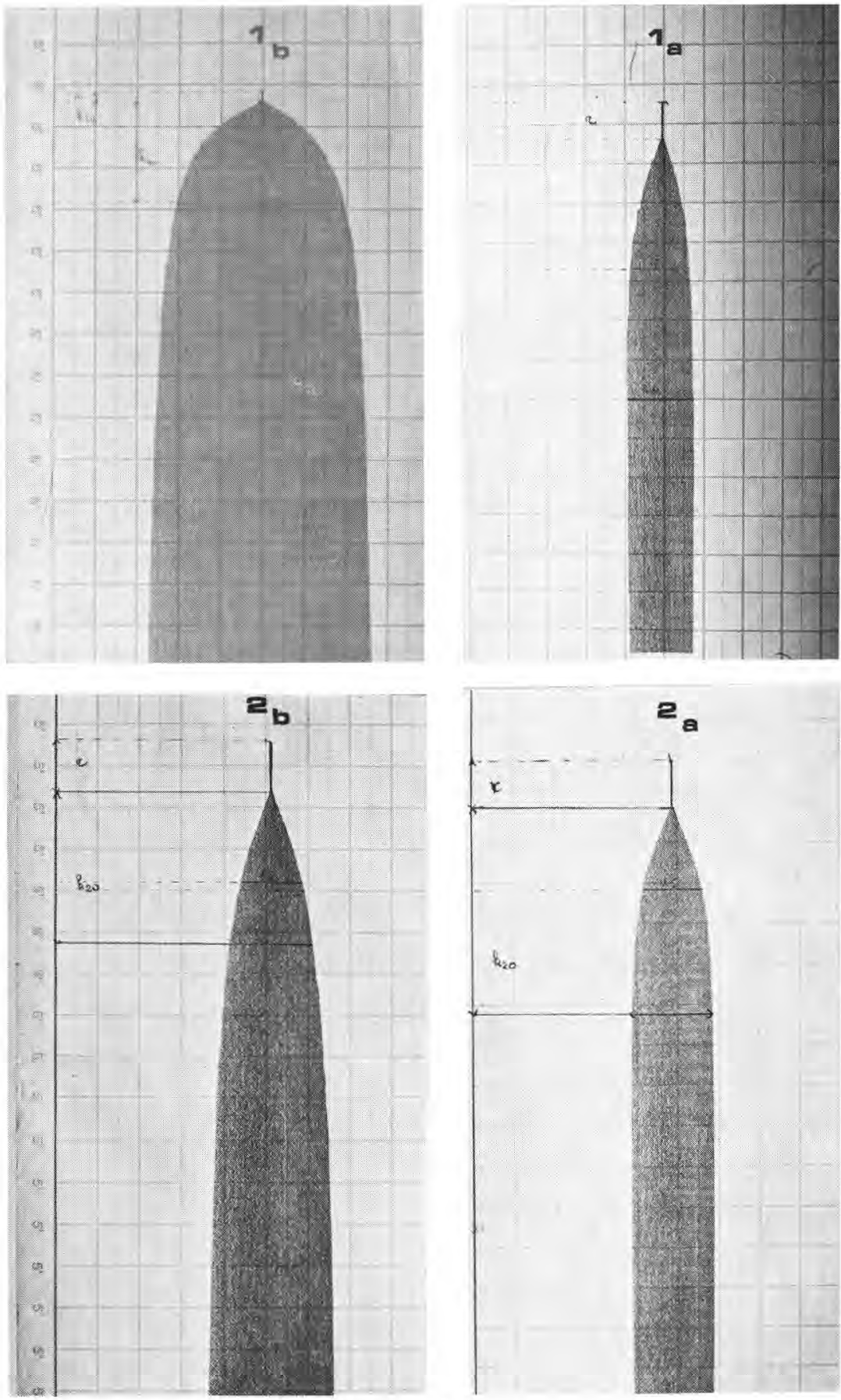

fig. 2

Thrombélastogrammes : I. Pepsine, II. Chymosine. a) Lait non traité ; b) Lait traité (la dose d'enzyme est la même pour a et b). 


\section{TABLEAU 8}

Modification des paramètres de la coagulation du lait irradié

\begin{tabular}{|c|c|c|c|c|}
\hline & \multirow{2}{*}{$\begin{array}{l}\text { Diminution } \\
\text { du pH }\end{array}$} & \multicolumn{3}{|c|}{$\begin{array}{l}\text { Facteur de réduction ou d'allongement } \\
\text { (irradiation de } 60 \mathrm{mn} \text { ) }\end{array}$} \\
\hline & & $\underset{\text { Temps }}{\underset{(\mathrm{r})}{\text { de coagulation }}}$ & $\underset{(\mathrm{Am})}{\text { Ampl. max. }}$ & $\mathrm{K}_{20} / \mathrm{r}$ \\
\hline Chymosine & $-0,04$ & $x 1,0$ & $\mathrm{x} 1,8$ & $\mathrm{x} 0,7$ \\
\hline Pepsine bovine & $-0,04$ & $\mathrm{x} 1,0$ & $\mathrm{x} 1,9$ & x 0,25 \\
\hline Pepsine porcine & $-0,04 /-0,02$ & $x 0,3 / x 0,4$ & $x 4,0 / x 3,3$ & $--/ \times 0,35^{*}$ \\
\hline Mm (Fro) & $-0,05 /-0,04$ & $\mathrm{x} 0,6 / \mathrm{x} 0,7$ & $x 2,0 / x 2,6$ & x $0,55 /$ x $0,45^{*}$ \\
\hline Mm (Ren) & $-0,04 /-0,04$ & $\mathrm{x} 0,5 / \mathrm{x} 0,6$ & x $2,5 /$ x 3,5 & $--/ \times 0,4^{*}$ \\
\hline Ep & $-0,04$ & $\mathrm{x} 0,6$ & $\mathrm{x} 2,8$ & $x 0,2$ \\
\hline $\mathrm{Mp}$ & $-0,05$ & $\mathrm{x} 0,5$ & $\times 3$ & $x 0,25$ \\
\hline
\end{tabular}

Facteur pour $\mathrm{K}_{15} / \mathrm{r}$.

TABLEAU 9. - Teneur en calcium soluble*

\begin{tabular}{l|c|c}
\hline & \multicolumn{2}{|c}{ Calcium } \\
\cline { 2 - 3 } & ultrafiltrable & non sédimentable \\
\cline { 2 - 3 } Lait cru non traité & $0,420(31,1)$ & $0,482(35,7)$ \\
Lait irradié $30 \mathrm{mn}$ & $0,460(34,1)$ & $0,484(35,8)$ \\
Lait irradié $60 \mathrm{mn}$ & $0,460(34,1)$ & $0,504(37,3)$ \\
& & \\
\hline
\end{tabular}

* Valeurs ramenées en g p. 1 de lait.

Entre parenthèses : p. 100 du Ca total $(1,35$ g p. l). 
Le tableau 9 présente les résultats du dosage avant et après traitement aux ultrasons. On constate que la quantité de calcium soluble augmente légèrement après irradiation, mais la variation est peu significative.

Il n'est actuellement pas possible d'expliquer clairement pourquoi l'irradiation modifie l'aptitude à la coagulation, dans les cas où on ne peut invoquer la disparition d'un inhibiteur ; ni d'expliquer le comportement de la pepsine porcine dans le lait irradié, qui la distingue nettement de la pepsine bovine et de la chymosine. Dans la poursuite de ces recherches, nous avons entrepris des analyses électrophorétiques et une étude de suspension micellaire par l'examen au microscope électronique.

\section{R é s u m é}

L'irradiation des enzymes coagulantes par les ultrasons cavitants à $15^{\circ} \mathrm{C}$ provoque une perte de l'activité protéolytique qui est parallèle à la perte d'activité coagulante. La chymosine et la pepsine bovine sont rapidement inactivées ; la pepsine porcine est plus résistante ; les enzymes fongiques sont peu ou pas sensibles à l'irradiation.

L'irradiation du lait produit des effets différents selon qu'il s'agisse de lait cru ou de lait reconstitué. Ce dernier est rendu un peu moins coagulable. Le lait cru donne le même temps de coagulation par la chymosine; dans le cas des enzymes de Mucor il y a une levée de l'inhibition naturelle.

Lorsqu'on irradie le mélange réactionnel (lait + enzyme) on observe peu de changement dans le temps de coagulation par la chymosine. Le lait protège l'enzyme de la dénaturation. Les enzymes de Mucor voient leur activité coagulante accrue.

Les paramètres rhéologiques sont fortement modifiés dans le lait irradié, surtout dans le cas de la pepsine porcine et des enzymes fongiques. L'irradiation accélère le raffermissement du caillé et accroît la fermeté finale. La pepsine porcine se distingue beaucoup de la pepsine bovine et de la chymosine dans son comportement. Il ne semble pas qu'un changement dans l'équilibre du calcium soit en cause.

\section{S u m m a r y}

\section{EFFECTS OF ULTRASONIC CAVITATION ON THE MILK COAGULATION BY THE CLOTTING ENZYMES}

The irradiation of clotting enzymes by ultrasonic cavitation at $16^{\circ} \mathrm{C}$ causes a loss in the proteolytic activity. The chymosin and the bovine pepsin are quickly inactivated; the porcine pepsin is more resistant and the fungal enzymes are few or not sensitive to the ultrasonic cavitation. 
The irradiation of milk induces different effects for raw milk and reconstitued milk. The latter became less coagulable. The raw milk gives the same coagulation time by the chymosin. In the case of Mucor enzymes, there is a removal of the natural inhibition.

When the mixture milk-enzyme is irradiated, we observe little or none change in the coagulation time by the chymosine. The milk protects the enzyme against the denaturation. The clotting activity of Mucor enzymes is increased.

The rheological parameters are greatly changed, especially for the coagulation by porcine pepsin and fungal enzymes. The irradiation accelerates the hardening of the curd and augments the final firmness. The porcine pepsin behaviour is very different from that of bovine pepsin and chymosin. The change in calcium equilibrium is probably not concerned.

Reçu pour publication en juillet 1978.

\section{Bibliographie}

[1] Alais (C.), Mocouot (G.), Nitschmann (H. S.) und Zahler (P.) (1953). - Das Lab und sein Wirkung auf das casein der Milch. VII. Uber die Abspaltung von Nicht-Protein-Stickstoff (NPN) aus casein durch Lab und ihre Bezichung zur Primärreaktion der Labgerrinnung der Milch. Helv. Chim. Acta, 36, 1955.

[2] Alais (C.), Ducroo (P.) et Delecourt (R.) (1974). - Inhibition d'une protéase coagulante fongique dans le lait cru. Le Lait, 52, 517-527.

[3] Alais (C.) et NovaK (G.) (1968). - Etude d'une enzyme coagulante microbienne dérivée de Endothia parasitica. Le Lait, 48, 393.

[4] Alais (C.) et Lagrange (A.) (1972). - Etude biochimique d'une protéase coagulante produite par Mm. Le Lait, 52, 407.

[5] Beck (J.) et Rouyer (M.) (1951). - Etude de la coagulation du lait par la présure. I. Action des ultrasons. Bull. Soc. Chim. Biol., 33, 69.

[6] Delfour (A.), Jolles (J.), Alais (C.) and Jolles (P.) (1965). - Caséino-glycopeptides : characterization of a methionine residue and of the N-terminal sequence. Biochem. Bioph. Res. Comm., 19, 452.

[7] Frentz (R.) (1965) . - Application de la thrombélastographie de Hartert à l'étude de la coagulation du lait. Le Lait, 45, 489.

[8] Guerin (J.), Rambaud (J. M.) et Alais (C.) (1974). - Détermination de l'aptitude fromagère des poudres de lait écrémé Spray. XIX ${ }^{e}$ Congrès International de Laiterie, New-Dehli F. 872.

[9] Raharintsoa (C.), Gaulard (M. L.) et Alais (C.) (1977). - Etude de l'action des ultrasons cavitants sur quelques enzymes coagulantes. Le Lait, 57, 631.

[10] Ramet (J. L.) et Alais (C.) (1972). - Etude d'une protéase coagulante produite par Mucor miehei. II. Utilisation de la Rennilase dans la fabrication des fromages à pâte molle. Le Lait, 52, 654 .

[11] Samuelson (E. G.) (1962). - Expérimentation sur le goût " de soleil 》 du lait ; di et tripeptides de la méthionine. 16th International Dairy Congress, vol. A, section $1: 2$, Copenhagen, 552-559.

[12] Tarodo de la Fuente (B.), Alais (C.) et Frentz (R.) (1969), - Etude de la coagulation du lait et de la synérèse par la méthode thrombélastographique. Le Lait, 49, 400.

[13] Verain (A.) et Despaux (E.) (1958). - Action des ultrasons sur le complément et ses composants. Annales de l'Institut Pasteur; 95, 125. 